\title{
System Integration of PLM and ERP Based on Cloud computing
}

\author{
Guochun Tang \\ Department of Information, QiongTai teachers' college, Haikou 571100, China
}

\begin{abstract}
It describes the difference and relationship between product life cycle management (PLM) and enterprise resource planning (ERP) system, analyzes the interaction of two system data, and obtains the integration content. It discusses the technology and solutions on the integration of ERP and PLM based cloud computing, puts forwards a kind of eight levels two-way transferring integrated framework of PLM and ERP based on cloud service, and points out the development trend of ERP system integration, and provides the basis to select integration schemes for enterprises.
\end{abstract}

Keywords-system integration; PLM; ERP; cloud computing.

\section{INTRODUCTION}

The PLM eliminates effectively the information island on CAX and the ERP eliminates effectively the information island on financial management, production management, cost management, materials demand management. Usually PLM system and ERP system data is independent, and database, data formats are different. Because two system integrations are not ideal, this becomes the enterprise obstacles to further implement the information. The same product process and the formation of PLM and ERP are closely related. If the enterprise integrates PLM and ERP system, it can share design and manufacturing data through a automation process, and improves the organization's data integrity, ensures that all the departments can get the latest and the most accurate product data, improves the enterprise's competitive power, and brings the huge economic benefits to the enterprise. At present, most of scholars put forward the integrated method based on the PDM and ERP mathematical model, the integration method based on data interface to realize the PDM and ERP, and the integration method based on the PDM and ERP system XML, etc. Cloud computing technology makes it more convenient to configure and maintain PLM and ERP, can be easily integrated in any one of the main application service。 The system of PLM and ERP based on cloud computing can better with a plurality of different kinds of application services together than the enterprise the internal operation of the PLM and ERP system. This paper analyzes the interaction of two system data, and obtains the integration content, and discusses the technology and solutions on the integration of ERP and PLM, puts forwards a kind of eight levels two-way transferring integrated framework of PLM and ERP based on cloud computing.

\section{PLM AND ERP SYSTEM INTEGRATION ANALYSIS}

\section{A. PLM and ERP system integration content}

PLM system takes manufacturing Product data as a core to solve the whole life cycle of different types of data management, process management, and different department and cross area and supply chain coordination, from users' demand, order information, product, process development, design, manufacture, maintenance; It changes the enterprise information means of traditional design, manufacturing and operation management mode, and provides the unification of the platform for Enterprise product innovation of information integration and business process . ERP makes enterprise internal various sectors integrate, including finance, accounting, production, material management, quality management, sales and distribution, human resource management, supply chain management, using the information technology integration. the manufacturing BOM of ERP system comes from PLM system, PLM management system of information have the CAD product information, including such as parts attribute, product structure relation and so on, also from CAPP system to produce management process information, including the working procedure of treatment, id number, working hours, the consumption of materials. This information is the basic data of enterprise production management, is ERP system input data. PLM and ERP cloud computing model can be divided into private and public cloud according to different deployment modes, and also can be divided into different IaaS mode, PaaS mode and SaaS mode according to the service mode. taking into account deployment phase conflicts among IaaS mode. PaaS mode and private cloud, cloud computing construction model of PLM and ERP is divided into four categories: private cloud model, IaaS model, PaaS model and SaaS model, the first 3 modes ' cloud computing providers and ERP suppliers often is not a subject, the fourth model of cloud computing providers and ERP suppliers is a subject that is cloud computing ERP suppliers. PLM and ERP system information integration model as shown in figure 1 . 


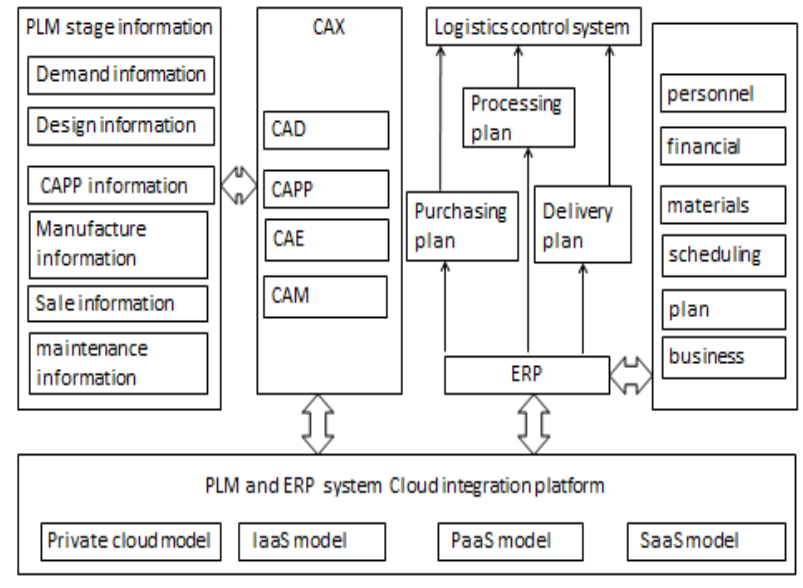

Figure 1. PLM and ERP system Cloud integration model

\section{B. PLM and ERP system integration methods}

At present the system integration methods PLM with ERP mainly displays in Encapsulation integration scheme, Active integration scheme, and Passive integration scheme, Interface integration scheme. (1)Encapsulation integration scheme : Encapsulate the PLM and ERP system. "Encapsulation " makes the object's properties and operation method seal in the definition of the object, it describes the visible module external interface with operating set, ensure that $t$ object interface and object internal expression is independent. The internal structure attributes and operation method of object is invisible, only the external interface is the only visible parts. (2) Active integration scheme: PLM will input the information needed to ERP directly ERP system database. This means asks detailed understanding of ERP system internal database structure, and ERP system allows PLM system to write data (i.e., has written permissions). Using active forms, the synchronicity of the information is good in the ERP and PLM system ,but there are some problems in safety, if writing the data conflict appears, namely PDM system write data to the ERP system at the same time, ERP system also write the data itself. General for large ERP system such as ORACLE, SAP, and this way is not inadvisable.(3) Passive integration scheme: This model is just instead with active integrated, ERP system read the needed data from PLM system; it will be written to the database. Using the passive interface scheme, the synchrony of ERP and PLM is better, stronger than active safety. General the interface work is completed by ERP software provider; it is suitable for self-development ERP system. (4) Interface integration scheme: PLM and ERP both sides provide the development tools, development data interface, make the ERP can directly access to information from PLM, PLM also can get feedback through the interface from ERP information, so as to achieve the two-way transfer information. According to their respective interface requirements PLM and ERP provides the tool accessed to database for the other party, namely API is called to exchange information; PLM and ERP system generate middling file or data table from the information needed, ERP system directly read the following information middling file or data table, and write to the database, this way demands both sides do some development work.

\section{The two-way transferring integration of ERP and PLM based on Cloud Service}

In order to solve the business integration need, The Cloud Service can accomplish certain tasks function of independent entity through connections. Cloud Service is a component model; the application of different function units (called service) is connected through the definition of good interface and contract. It is independent among realization of hardware platform service, operating system and programming language. This makes the service building in heterogeneous environment be a unified and general way together. In the integration methods of PLM and in ERP system, the first level synergy is data one-way transmission, namely from PLM system data transfer to the ERP system. The technology is mature, and realization roughly as follows: (1)First completing design work in CAD and PDM, distributing material code, and establishing the design of the product tree.(2)completing in process in CAPP.3making design and process output to the ERP can import data files.(4)ERP system will import to data file , and establish the material master files and material list. The second collaborative level is required to realize the close-loop feedback between PLM and ERP. Close-loop feedback makes departments cooperate and restrict, so as to effectively avoid blind decision-making and execution. the second level collaborative process Suggestions of PLM and ERP are as follows:11ERP system provides optimizing material list.2)Technical personnel select complete design from the choice in material list.(3)If optimization in material list do not have the appropriate material, technical personnel need to add material, can update optimizing material list after handing in other department to assess.(4) Setting up product design tree.5)completing in technology In CAPP, and choosing the load of saturated equipment need to be evaluated by more departments. (6)making design and process output to the ERP can import data files. (7)ERP system will import to data file, establish the material master files and material list. In the two-way transferring integration of ERP and PLM based on cloud service, can choose ESB as a system integration platform, general framework as shown in figure 2 : 


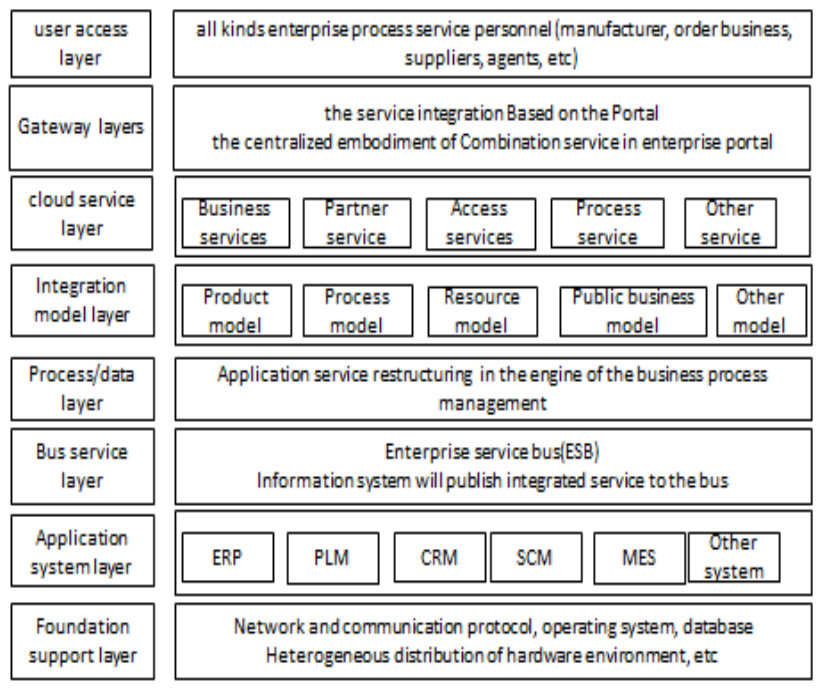

Figure 2. The two-way transferring integration of ERP and PLM based on Cloud Service

In the two-way transferring integration of ERP and PLM based on cloud service, the enterprise all application system interacts with other application system data through the enterprise service bus. As Figure 3 shows.

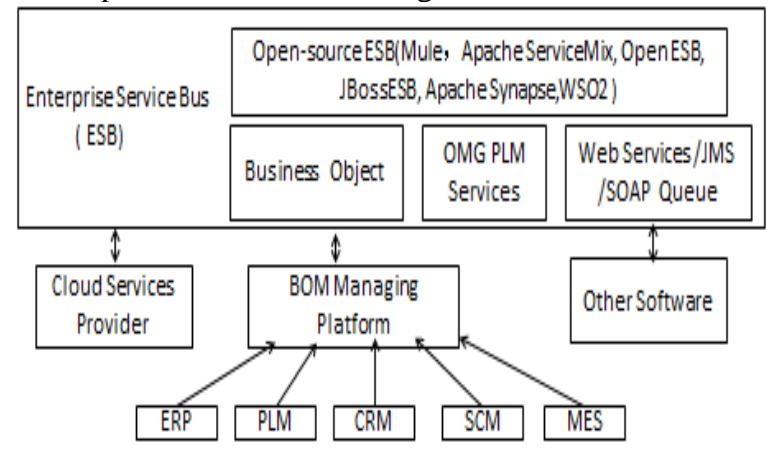

Figure 3. PLM and ERP system ESB integration model Based on cloud servcie

Each application system makes their particular service develop into adapter, carry on the service encapsulation, and publish to the system bus. All the system of participating in the integration are only consumer service bus service standards, doesn't care service is by which the system is provided, how to concrete realization of service. So that through ESB and other application system, fully realize the coupling between the system, makes the changes of a system interface definition do not will directly affect the other system, thus make the "loose coupling" of the system architecture among the system .

\section{The integration Suggestions ERP and PLM system to enterprise}

No matter is the first enterprise ERP or PLM, should first consider the ERP and PLM as a whole, according to the whole plan, implement step by step. Enterprise first implement PLM or ERP, can judge according to the actual situation of enterprise: on one hand, the enterprise is to see to pay more attention to research and development, or pay more attention to the integration of resources; On the other hand, to look at the information level of enterprise itself. For example, if the enterprise first implements PLM system, the data ERP system may need to should be fully considered. Only understanding the system, understanding the customer's suppliers can really help the enterprise to solve better the integration of ERP and PLM. Like SAP, oracle, UFIDA ERP supplier, and Dassault, PTC, Siemens, CAXA, PLM suppliers, very understand the integration demand of PLM to ERP.

\section{PLM AND ERP SYSTEM INTEGRATION DEVELOPMENT TREND}

PLM and ERP information construction is the combining the development process of modern enterprise management ideas and enterprise production, the process is not just a software system using the process, is a set of advanced management ideas and methods in enterprise different levels of full application. PLM and ERP fusion is a development trend, becomes the issues of manufacturing information and implementation. In addition, as SOA, virtualization, cloud computing and other emerging technology maturity, let the complete cloud computing architecture become possible, the model of ERP and PLM constructed in the cloud computing has become a new challenge and inevitable. For this cloud era the identity of ERP, PLM manufacturers need to be adjusted, it no longer is a single products and solutions provider, and ready to operators' transformation, to include more safety and open architecture, and carrying more third party products. In addition to information integration, service integration, process integration, and also to human and intelligent for integration, to provide integrated solutions of ERP and PLM to users , and cloud service to help enterprises to realize the information of the higher application value.

\section{SUMMARY}

This paper discusses the technology and solutions on the integration of ERP and PLM, puts forwards a kind of eight levels two-way transferring integrated framework of PLM and ERP based on cloud computing. In the future, the model of ERP and PLM integrated suppliers based on Cloud computing will become more and more popular.

\section{ACKNOWLEDGMENTS}

This work was supported by the Natural Science Foundation of Hainan Province, China (No. 614247).

\section{REFERENCES}

[1] QiaoLiHong, ZhangYiZhu, Change Information Integration and Control between PDM and ERP, Computer integrated manufacturing systems [J], 2008(05):906-910

[2] YANG Nan, LI Dong-bo, TONG Yi-fei Architecture for service-oriented ERP based on cloud computing platform, manufacturing automation[J],2012,34(10):74-77

[3] LiuShiJun, zhang yong, YangChengWei,, Business System of small and medium-sized enterprises Based on the SaaS service, Journal of 
southeast university (natural science edition) [J],2011,41(03):459-462

[4] DaiGuoliang. Study on ERPII Collaborative Business System Based on Cloud Computation, Logistics technology[J],2014,33(2):304-306

[5] Byeong-Eon Lee \& Suk-Hwan Suh, An architecture for ubiquitous product life cycle support system and its extension to machine tools with product data model, Int J Adv Manuf Technol (2009) 42:606-620

[6] Farouk Belkadi.Nadège Troussier.Benoit Eynard, Collaboration based on product lifecycles interoperability for extended enterprise, Int J Interact Des Manuf (2010) 4:169-179

[7] Lee S, Han S, Mun D. Integrated management of facility, process, and output: data model perspective. Sci China Inf Sci, 2012, 55: 994-1007

[8] eongsam Yang \& Soonhung Han \& Matthias Grau, OpenPDM-based product data exchangeamong heterogeneous PDM systems in a distributed environment, Int J Adv Manuf Technol (2009) 40:1033-1043

[9] Aobing Sun, Tongkai Ji, Qiang Yue IaaS Public Cloud Computing Platform Scheduling Modeland Optimization Analyzation, 2010 Third International Conference on Education Technology and Training (ETT)586-589

[10] K. Chen, W.M. Zheng, "Cloud Computing: System Instance and CurrentState”, Journal of Software, Vol. 20, NO. 5, pp 1337-1348, 2009.

[11] CuiJian, QiGuoNing, juyangjian etc, Management Model on Requirement Information Oriented Product Life Cycle, Computer integrated manufacturing systems [J],2007,13(12):2407-2414

[12] SUN Yong, HAN Liang, LI Ni, Research and Application of PLM in SBA[J], Journal of System Simulation,2008,20(19):5167-5168 